\title{
Characterization of colloidal nanoparticle suspensions using the third harmonic generation at interfaces
}

\author{
${ }^{1,2}$ Multian V. V., ${ }^{2}$ Le Dantec R. and ${ }^{1}$ Gayvoronsky V. Ya. \\ ${ }^{1}$ Institute of Physics of NASU, 46 Nauky Avenue, 03028 Kyiv, Ukraine, \\ e-mail: vlad@iop.kiev.ua \\ ${ }^{2}$ Université Savoie Mont Blanc, SYMME, F-74000 Annecy, France
}

Received: 06.03.2018

\begin{abstract}
We report the studies of third harmonic generation efficiency using an interface-scanning technique for colloidal suspensions of harmonic $\mathrm{ZnO}$ nanoparticles under nanosecond-range pulsed laser excitation at $1064 \mathrm{~nm}$. The harmonic nanoparticles represent a new type of biomarkers for multiphoton imaging, which generate efficiently second-, third- and higher-order optical harmonics. Using the reference data for fused silica, the characteristic orientationaveraged nondegenerate cubic nonlinear optical susceptibility $\sim 10^{-10}$ esu is obtained for the $\mathrm{ZnO}$ nanoparticles with the mean sizes $40-150 \mathrm{~nm}$. The third harmonic generation efficiency increases with increasing nanoparticle size and achieves the reference data known for the bulk $\mathrm{ZnO}$ crystals. The technique suggested by us can be applied in nondestructive express diagnostics of nanoparticles, when characterizing their nonlinear optical properties, studying the effect of their size and shape, and further improving their harmonic generation efficiency.
\end{abstract}

Key words: harmonic nanoparticles, multiphoton imaging, optical harmonic generation

PACS: $42.65 . \mathrm{Ky}$

UDC: $535.3,535-1,535-3$

\section{Introduction}

Harmonic nanoparticles (HNPs) [1] represent a new family of biomarkers for multiphoton imaging [2] and exerting optical contrast by the second-, third- and higher-order optical harmonic generation. This type of biomarkers can be excited at specific resonances and a presence of even harmonics is directly associated with a noncentrosymmetric character of their lattice structure [3-7]. Very recently, several authors have observed simultaneous generation of second, third (TH) and fourth harmonics by individual HNPs in the microscopy studies [8-10]. Simultaneous detection of these signals, along with additional tunability of response, can be used for sensing and imaging to increase selectivity against background. However, proper characterization of the nonlinear optical properties of nanoparticles (NPs) with different sizes and surface functionalization is still an interesting issue. Characterization of second harmonic generation efficiency $\left\langle\chi_{N P S}^{(2)}\right\rangle$ can be done using a hyper-Rayleigh scattering effect readout versus a wellknown response of PNA molecules as a reference [11]. One of the approaches used to estimate the average TH generation (THG) efficiency $\left\langle\chi_{N P S}^{(3)}\right\rangle$ is based on a two-step procedure. The first is measuring of the second harmonic generation efficiency $\left\langle\chi_{N P S}^{(2)}\right\rangle$ of HNPs and the second step is comparing the scattering responses at the TH $\left(I_{3 \omega}\right)$ and second harmonic $\left(I_{2 \omega}\right)$ frequencies under the same laser pump level $I_{\omega}$, resulting in the following relation: 


$$
\left\langle\left|\chi_{N P S}^{(3)}\right|^{2}\right\rangle \propto\left\langle\left|\chi_{N P S}^{(2)}\right|^{2}\right\rangle I_{3 \omega}\left(I_{2 \omega} I_{\omega}\right)^{-1}
$$

Notice that this indirect technique for calibrating the THG efficiency has a number of drawbacks. In particular, it requires high pump intensities $I_{\omega}$, whereas the two-step procedure decreases the overall precision.

The other approach is direct. It is based on the THG interface-scanning technique [12-14]. The latter has been first designed for analyzing the THG response efficiency of liquids and gases in the quartz cells. This can be accomplished through comparing the THG signal at a filled-cell interface with the corresponding signal at the quartz/air interface as a reference.

In the present work we apply, for the first time, the direct approach to studies of THG efficiencies for the colloidal suspensions with different HNP concentrations. We characterize the nonlinear optical properties of ZnO NPs and study the influence of size of the NPs on these properties [15].

\section{Methods and materials}

The THG interface scanning technique described in Ref. [12] has been initially designed for studying homogeneous media. It allows estimating the cubic nonlinear susceptibility $\chi^{(3)}(3 \omega)$ of a sample in a cell by comparing it with the known parameter $\chi_{g l}^{(3)}(3 \omega)$ of a cell material, typically fused silica [16]. The susceptibility $\chi^{(3)}(3 \omega)$ is proportional to the square root of the ratio of $\mathrm{TH}$ signals detected at sample/glass $\left(I_{s}\right)$ and glass/air $\left(I_{a}\right)$ interfaces:

$$
\chi^{(3)}(3 \omega) \sim \chi_{g l}^{(3)}(3 \omega)\left(1 \pm\left(I_{s} / I_{a}\right)^{1 / 2}\right) \text {. }
$$

According to the set of measurements performed for different solvents with the known cubic susceptibilities, $\chi_{s}^{(3)}$ the positive sign in Eq. (1) should be used in calculations, as explained in Ref. [12].

In case of inhomogeneous systems like colloidal NP suspensions with very low NP volume fractions $f$, the effective susceptibility $\chi_{c o l}^{(3)}$ of the colloidal NP suspension can be written as [17]

$$
\chi_{c o l}^{(3)}(3 \omega)=f\left(\frac{3 \varepsilon_{b}(3 \omega)}{\varepsilon_{a}(3 \omega)+2 \varepsilon_{b}(3 \omega)}\right)\left(\frac{3 \varepsilon_{b}(\omega)}{\varepsilon_{a}(\omega)+2 \varepsilon_{b}(\omega)}\right)^{3}\left\langle\chi_{N P S}^{(3)}(3 \omega)\right\rangle+\chi_{s}^{(3)}(3 \omega),
$$

where $\varepsilon_{a}$ and $\varepsilon_{b}$ denote the permittivities of the NPs and the solvent, respectively.

In the framework of the present approach, we have measured $\chi_{c o l}^{(3)}$ for diluted colloidal suspensions with different concentrations of ZnO NPs. This enables evaluating the orientationaveraged THG susceptibility $\left\langle\left|\chi_{N P s}^{(3)}\right|^{2}\right\rangle^{1 / 2}$ of the NPs (referred to as $\left\langle\chi_{N P s}^{(3)}\right\rangle$ further on) and the $\chi_{s}^{(3)}$ parameter of the solvent, thus allowing one to check the validity of the experimental data.

The experimental setup is shown in Fig. 1. A YAG laser (Wedge HB, Bright solutions, with the wavelength $1064 \mathrm{~nm}$, the pulse width $1 \mathrm{~ns}$ and the repetition rate $1 \mathrm{kHz}$ ) was used as an excitation source. The laser beam was focused by a lens $L(f=5 \mathrm{~cm})$ at a flow cell mounted on a high-precision translation stage for the interface scanning along the $Z$ direction. The THG signal in the forward direction was collected by lenses and measured by a photomultiplier tube PMT (Hamamatsu H10721-210) with edge-pass and band-pass (355 $\pm 5 \mathrm{~nm}$ ) filters placed in front of it for removing the pump beam and extracting the $\mathrm{TH}$ signal at $355 \mathrm{~nm}$. A half-wave plate (not shown in Fig. 1) and a polarizing cube PC were used to adjust the intensity of horizontally 


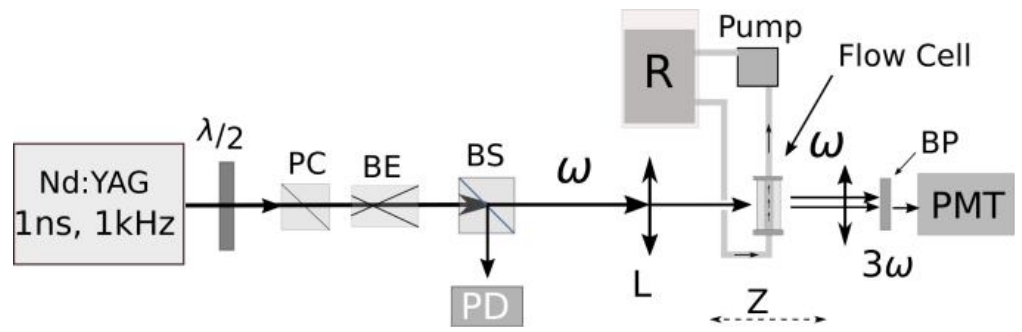

Fig. 1. Experimental setup of THG interface scanning technique: $B S$ - beam splitter; $L$ - focusing lens; PD - photodiode; PMT - photomultiplier tube; PC - polarizing cube; BP - band-pass and edge-pass filters; $\mathrm{BE}$ - beam expander; $\mathrm{R}$ - reservoir with colloidal suspension.

polarized excitation beam. A beam expander BE with a pinhole placed after its focal plane was used in order to optimize the beam size. The output power variation was monitored by a Si-based photodiode PD. A knife-edge technique was used to measure the beam diameter at different positions and estimate the waist size. It was equal to $w_{0} \approx 15 \mu \mathrm{m}$, with the confocal parameter $b \approx 0.6 \mathrm{~mm}$.

The above setup configuration allowed us to obtain an optimal beam waist volume in terms of the quantity of irradiated NPs and to resolute spatially the TH signals from the interfaces. The thermal effects in the measurement cell, the NP-concentration fluctuations and their sticking on the cell walls were also reduced. For avoiding optical damage of the NP suspensions and silica-glass walls, the laser pulse energy was set below $20 \mu \mathrm{J}$. For the case of $1 \mathrm{kHz}$ pulse train, a flow cell with a $2 \mathrm{~mm}$ light path between a $5 \mathrm{~mm}$ thick UV fused silica windows was applied to prevent signal fluctuations and non-reproducible THG trends, which would have otherwise taken place in the case of static cell. A peristaltic pump connected to a $\sim 50 \mathrm{~mL}$ main reservoir provided a flow rate of $\sim 60 \mathrm{~mL} / \mathrm{min}$. Continuous magnetic stirring avoided significant variations of the NP concentration during the scanning. A comparison of the irradiated waist volume with the mean velocity $\sim 1 \mathrm{~cm} / \mathrm{s}$ of the suspension gave us an estimate of the refresh rate of about $0.5 \mathrm{kHz}$, thus providing new suspension volumes per almost each laser shot.

The above technique was used to study three commercial $\mathrm{ZnO}$ nanopowders with different sizes of nanocrystals (see Fig. 2): 90-200 nm for a ' $Z n O 1$ ' sample (NanoAmor Inc.), $40-100 \mathrm{~nm}$ for a ' $\mathrm{ZnO} 2$ ' sample (NanoTek, Alfa Aesar), and about $40 \mathrm{~nm}$ for a ' $\mathrm{ZnO}$ ' sample (NanoAmor Inc.). The procedures of preparation of stable colloidal suspensions in ethanol were carried out in two steps. On the first stage, $200 \mathrm{~mL}$ of initial solution with the NP concentration $1 \mathrm{mg} / \mathrm{mL}$ was placed for $2 \mathrm{~h}$ in an ultrasonic bath. The second stage lasted a couple of weeks, when a large-scale agglomerates sedimentation took part, with consequent extraction of the supernatant.

The final supernatant prepared in this way showed low sizes and narrow size distribution, as estimated from a dynamic light scattering. The NP concentration was measured by weighing the evaporated supernatant. A dried drop on a carbon-film-coated copper grid was used for TEM imaging (JEOL $2100 \mathrm{HT}$ ) and relatively broad size and shape polydispersities were observed for
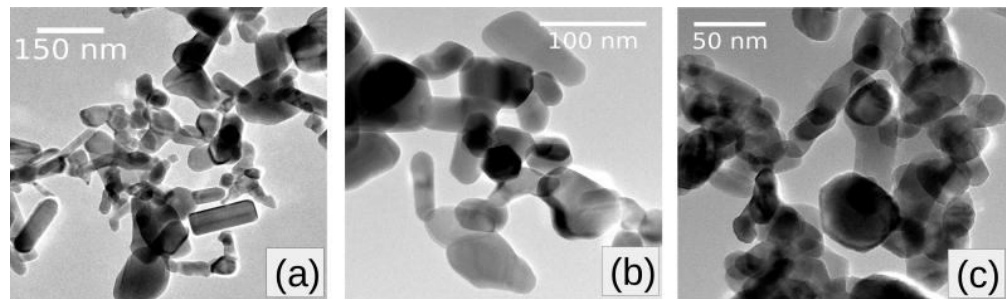

Fig. 2. TEM images of (a) $\mathrm{ZnO} 1$, (b) $\mathrm{ZnO} 2$, (c) $\mathrm{ZnO} 3$ nanocrystals dispersed in ethanol. 
Table 1. Nonlinear susceptibilities $\left\langle\chi_{Z n O}^{(3)}\right\rangle$ estimated with our THG interface scanning technique.

\begin{tabular}{ccc} 
Sample & $d, \mathrm{~nm}$ & $\left\langle\chi_{\text {ZnO }}^{(3)}\right\rangle, 10^{-10}$ esu \\
\hline $\mathrm{ZnO3}$ & $40 \pm 20$ & $1.3 \pm 0.3$ \\
$\mathrm{ZnO} 2$ & $100 \pm 25$ & $2.2 \pm 0.2$ \\
$\mathrm{ZnO1}$ & $145 \pm 40$ & $2.6 \pm 0.2$
\end{tabular}

each of our $\mathrm{ZnO}$ samples. The main parameters of our samples are gathered in Table 1. The magnitude of the cubic susceptibility measured for ethanol $\left(\chi_{s}^{(3)}=(1.9 \pm 0.2) \times 10^{-14} \mathrm{esu}\right)$ demonstrated a good agreement with the reference data $(1.7 \pm 0.1) \times 10^{-14}$ esu [18] and proved the validity of our technique.

\section{Results and discussion}

We have performed the THG efficiency measurements for the three kinds of colloidal NP suspensions (see Table 1), using nanosecond laser pulses at $1064 \mathrm{~nm}$. A typical example of the TH-signal scan across the flow cell is presented in Fig. 3. It corresponds to the suspension of $\mathrm{ZnO} 1$ nanocrystals dispersed at $1.4 \times 10^{-2} \mathrm{mg} / \mathrm{mL}$ in ethanol. Four THG peaks $T H_{1-4}$ are generated within the cell volume at each interface of the cell, with the TH scattering contribution in forward direction. This TH scattering signal magnitude increases linearly with increasing NP concentration. This fact should be taken into account when retrieving correctly the interface THG intensity. The experimental data can be approximated by the function $I(z)=B G+\sum_{i=1}^{4} T H_{i}(z)+T H S(z)$, where $B G$ is the background level and $T H_{i}(z)$ the pseudoVoigt function [19] that models the shape of the THG peak at $i^{\text {th }}$ interface. The TH scattering from the cell volume, THS, is fitted by the plateau function:

$$
\operatorname{THS}(z)=S_{0}\left[1-\left(1+\exp \left\{\left(z-\mu_{1}\right) / \sigma_{1}\right\}\right)^{-1}-\left(1+\exp \left\{-\left(z-\mu_{2}\right) / \sigma_{2}\right\}\right)^{-1}\right]
$$

where $\mu_{2}-\mu_{1}$ is the plateau width, $\sigma_{i}$ the edge width and $S_{0}$ the scattering amplitude. The THG efficiency $\chi_{c o l}^{(3)}$ of the colloid suspension is determined from the amplitude ratio of the peaks

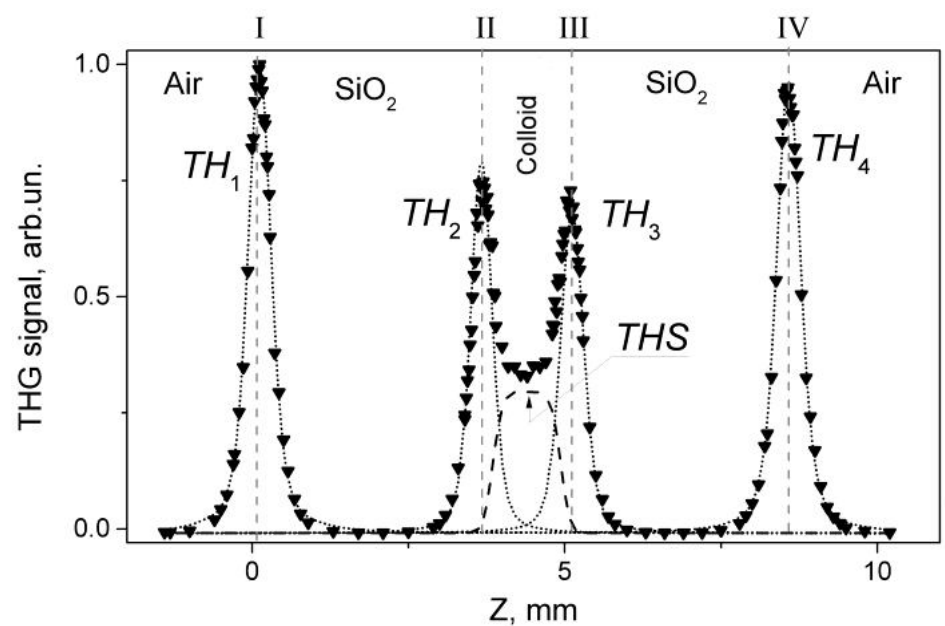

Fig. 3. Schematic representation of crossing the flow cell and implementation of the fitting procedure for the case of ' $\mathrm{ZnO} 1$ ' nanocrystals dispersed at $1.4 \times 10^{-2} \mathrm{mg} / \mathrm{mL}$ in ethanol. Experimental data (black triangles) are fitted with four THG peaks $T H_{i}$ (dotted line) measured from the interfaces I, II, III and IV and the THS plateau (dashed line) contribution.

Ukr. J. Phys. Opt. 2018, Volume 19, Issue 2 
$\mathrm{TH}_{3}(z)$ and $\mathrm{TH}_{4}(z)$ at the interfaces III and IV, which are the closest to the PMT detection unit (see Fig. 1). Their FWHMs have been used to estimate the effective beam waist confocal parameter at the corresponding interface.

For each given NP concentration in the suspension, we have checked the dependences of the TH signals detected at the colloid/silica and silica/air interfaces $\left(T_{3}(z)\right.$ and $T H_{4}(z)$, respectively) versus the peak laser intensity $I_{\omega}$ (see Fig. 4a). The latter has been varied while rotating the halfwave plate positioned before the PC (see Fig. 1). It has been revealed that the colloid/glass and ethanol/glass interfaces generate the $\mathrm{TH}$ signals with the typical slope $p=3.0 \pm 0.1$ on the $\log \log$ scale (at $I_{\omega}<0.8 \mathrm{GW} / \mathrm{cm}^{2}$ ). A further increase in $I_{\omega}$ reduces the THG efficiency, with the corresponding decrease in the slope $(p=2.3 \pm 0.1)$. This is due to self-action effects manifested in the suspension. The inset in Fig. 4 a displays the spectral response of the colloid with narrow bands of which spectral positions correspond to the second harmonics and $\mathrm{TH}$ of the pump radiation at $1064 \mathrm{~nm}$.

For all kinds of our $\mathrm{ZnO}$ NPs, we have performed a set of the scans across the flowing cell for different concentrations and volume fractions $f$ of the NPs in the suspension. The peak amplitude ratios $\mathrm{TH}_{3} / \mathrm{TH}_{4}$ thus obtained have been used to estimate the effective susceptibility $\chi_{\text {col }}^{(3)}$ for the whole $f$ range, basing on Eq. (1). We have obtained a linear dependence of $\chi_{\text {col }}^{(3)}$ upon $f$ for the stable diluted suspensions (see a typical graph in Fig. 4b referred to the ZnO1 HNPs). We have performed a checkout of these results, using the scans of the ethanol solvent only $(f=0)$ taken at the very beginning of the experiments and after the last measurement of the suspension characterized with the highest volume fraction. We have observed coincidence of the cubic nonlinear optical efficiencies $\chi_{s}^{(3)}$ of ethanol, thus demonstrating the absence of any pronounced contribution of the stuck NPs at the interface.

In the framework of the effective-medium approximation given by Eq. (2), we have analyzed the linear experimental concentration dependences of $\chi_{c o l}^{(3)}$ in order to estimate the orientation-averaged susceptibilities $\left\langle\chi_{Z n O}^{(3)}\right\rangle$ for each kind of the $\mathrm{ZnO}$ NPs (see Table 1). This reveals the impact of the NP size on the THG efficiency. One can see that the efficiency increases with increasing NP size $d$. In the case of ZnO1 NPs with $d \sim 150 \mathrm{~nm}$, it reaches the value $\chi^{(3)}=2.6 \times 10^{-10}$ esu at the pump-laser wavelength $1064 \mathrm{~nm}$, which is close to the reference data for the bulk $\mathrm{ZnO}$ (see Ref. [20]). In other words, the results obtained for the THG efficiency of the ZnO NPs agree well
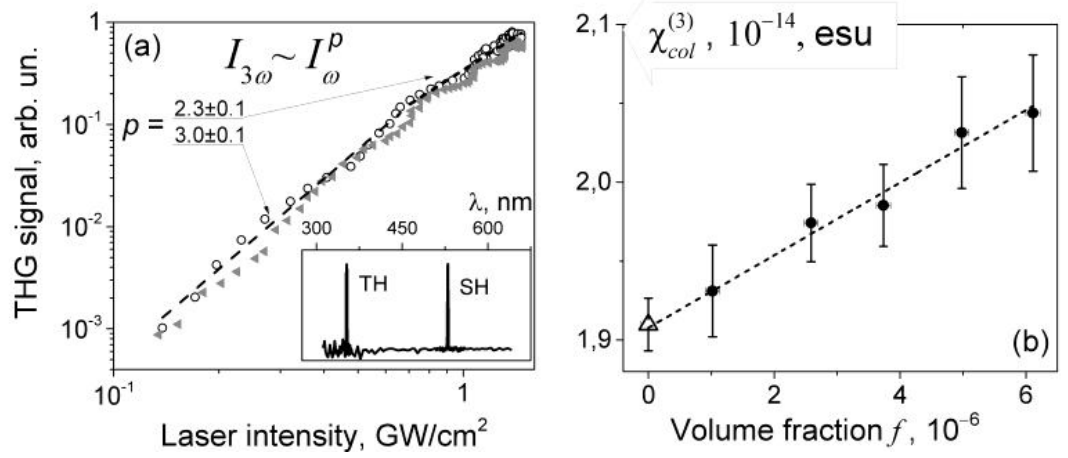

Fig. 4. (a) THG intensity at the colloid/glass interface versus the peak laser intensity at $1064 \mathrm{~nm}$ for $\mathrm{ZnO} 1$ sample (open circles) and ethanol (filled triangles); (b) The corresponding dependence of susceptibility $\chi_{\text {col }}^{(3)}$ on the volume NP fraction (filled circles). Open triangle denotes verification data point for the ethanol solvent taken after the concentration-dependence measurement set is finished (see explanations in the text). 
with the reference data for the bulk $\mathrm{ZnO}\left\langle\chi_{Z n O}^{(3)}\right\rangle=2.5 \times 10^{-10}$ esu [20], thus validating the experimental technique applied in the present work.

\section{Conclusion}

We study the THG efficiency for the colloidal ZnO NP suspensions, using the interface scanning technique and the regime of nanosecond-range pulsed laser excitation at $1064 \mathrm{~nm}$. The measurements are performed along the pump-beam propagation direction in the flow cell with thick fused silica sidewalls, in order to resolve the contribution of each of the interfaces. Basing on the reference data for the fused silica, we have obtained the THG efficiency of the ethanol solvent $\chi_{s}^{(3)}=1.9 \times 10^{-14}$ esu in the units that correspond to the reference data. The characteristic orientation-averaged parameter $\left\langle\chi_{Z n O}^{(3)}\right\rangle \sim 10^{-10}$ esu is obtained for the ZnO NPs with the mean sizes $40-150 \mathrm{~nm}$. A notable impact of the NP size on the THG efficiency is demonstrated. The efficiency increases up to $\left\langle\chi_{Z n O}^{(3)}\right\rangle=2.6 \times 10^{-10}$ esu with increasing NP size. In other words, it achieves the known reference data for the bulk $\mathrm{ZnO}$ [20] for the case of NPs with the largest size, $d \sim 150 \mathrm{~nm}$.

The technique suggested in this work can be applied to nondestructive express diagnostics of colloidal NP suspensions on the stage that follows the synthesis stage. This ensures characterizing the nonlinear optical properties of HNPs, as well as studying the effects of their size and shape. Moreover, it also enables efficient metrics for designing novel nanoprobes based on surfacemodified HNPs.

\section{Acknowledgment}

Financial supports from the PHC Dnipro Project $37824 \mathrm{WJ}$ are gratefully acknowledged. V. M. also thanks the French Embassy in Ukraine and the Auvergne Rhône Alpes Région (CMIRA 2016 - Accueil DOC) for travel and accommodation scholarships.

\section{References}

1. Bonacina L, 2013. Nonlinear nanomedicine: harmonic nanoparticles toward targeted diagnosis and therapy. Mol. Pharm. 10: 783-792.

2. Boyd R W. Nonlinear optics. Academic Press (2003).

3. Lippitz M, van Dijk M A and Orrit M, 2005. Third-harmonic generation from single gold nanoparticles. Nano Lett. 5: 799-802.

4. Schwartz O and Oron D, 2009. Background-free third harmonic imaging of gold nanorods. Nano Lett. 9: 4093-4097.

5. Butet J, Duboisset J, Bachelier G, Russier-Antoine I, Benichou E, Jonin C and Brevet P-F, 2010. Optical second harmonic generation of single metallic nanoparticles embedded in a homogeneous medium. Nano Lett. 10: 1717-1721.

6. Butet J, Brevet P-F and Martin O J F, 2015. Optical second harmonic generation in plasmonic nanostructures: from fundamental principles to advanced applications. ACS Nano. 9: 1054510562.

7. Locharoenrat K and Damrongsak P, 2015. Plasmonic properties of gold-palladium core-shell nanorods. Ukr. J. Phys. Opt. 16: 120-126.

8. Dai J, Yuan M-H, Zeng J-H, Dai Q-F, Lan S, Xiao C and Tie S-L, 2014. Controllable color display induced by excitation-intensity-dependent competition between second and third harmonic generation in ZnO nanorods. Appl. Opt. 53: 189-194. 
9. Extermann J, Bonacina L, Cuna E, Kasparian C, Mugnier Y, Feurer T and Wolf J-P, 2009. Nanodoublers as deep imaging markers for multi-photon microscopy. Opt. Express. 17: $15342-15349$.

10. Riporto J, Demierre A, Schmidt C, Campargue G, Kilin V, Urbain M, Dantec R L, Wolf J-P, Mugnier Y and Bonacina L, 2017. Dielectric nanoparticles as efficient RGB sources by second, third, and fourth harmonic generation excited at telecom wavelengths. ArXiv1707.08451 Phys.

11. Schmidt C, Riporto J, Uldry A, Rogov A, Mugnier Y, Dantec R L, Wolf J-P and Bonacina L, 2016. Multi-order investigation of the nonlinear susceptibility tensors of individual nanoparticles. Sci. Rep. 6: 25415.

12. Clay G O, Millard A C, Schaffer C B, Aus-der-Au J, Tsai P S, Squier J A and Kleinfeld D, 2006. Spectroscopy of third-harmonic generation: evidence for resonances in model compounds and ligated hemoglobin. J. Opt. Soc. Amer. B. 23: 932-950.

13. Barad Y, Eisenberg H, Horowitz M and Silberberg Y, 1997. Nonlinear scanning laser microscopy by third harmonic generation. Appl. Phys. Lett. 70: 922-924.

14. Barbano E C, Harrington K, Zilio S C and Misoguti L, 2016. Third-harmonic generation at the interfaces of a cuvette filled with selected organic solvents. Appl. Opt. 55: 595-602.

15. Multian V V, Uklein A V, Zaderko A N, Kozhanov V O, Lisnyak V V, Gayvoronsky V Ya, Boldyrieva O Y and Linnik R P, 2017. Synthesis, characterization, luminescent and nonlinear optical responses of nanosized $\mathrm{ZnO}$. Nanoscale Res. Lett. 12: 164.

16. Bosshard C, Gubler U, Kaatz P, Mazerant W and Meier U, 2000. Non-phase-matched optical third-harmonic generation in noncentrosymmetric media: cascaded second-order contributions for the calibration of third-order nonlinearities. Phys. Rev. B. 61: 10688-10701.

17. Hui P M, Cheung P and Stroud D, 1998. Theory of third harmonic generation in random composites of nonlinear dielectrics. J. Appl. Phys. 84: 3451-3458.

18. Débarre D and Beaurepaire E, 2007. Quantitative characterization of biological liquids for third-Harmonic generation microscopy. Biophys. J. 92: 603-612.

19. Pillai R S, Brakenhoff G J and Müller M, 2006. Analysis of the influence of spherical aberration from focusing through a dielectric slab in quantitative nonlinear optical susceptibility measurements using third-harmonic generation. Opt. Express. 14: 260-269.

20. Zappettini A, Amore F D, Pietralunga S M, Terio A and Martinelli M, 2004. Wavelength dependence of the third order non-linear coefficient in hydrothermally grown $\mathrm{ZnO}$ crystals. Phys. stat. sol. (c) Conf. 1: 997-1000.

Multian V. V., Le Dantec R. and Gayvoronsky V. Ya. 2018. Characterization of colloidal nanoparticle suspensions using the third harmonic generation at interfaces. Ukr.J.Phys.Opt. 19: 92 - 98

Анотація. Досліджено ефективність генерації третьої гармоніки за допомогою методики сканування поверхонь розділу для колоїдних суспензій гармонічних наночастинок ZnO при збудженні наносекундними лазерними імпульсами на довжині хвилі 1064 нм. Гармонічні наночастинки представляють собою новий тип біомаркерів для технології багатофотонних зображень, які з високою ефективністю генерують оптичні гармоніки другого, третього і більш високих порядків. Використовуючи еталонні дані для плавленого квариу, для наночастинок $\mathrm{ZnO}$ з середніми розмірами 40-150 нм одержано усереднену за орієнтацією характеристичну невироджену кубічну нелінійно-оптичну сприйнятність $10^{-10}$ од. СГСЕ. Ефективність генерації третьої гармоніки зростає зі збільшенням розмірів наночастинок $i$ досягає еталонних даних, відомих для кристалів об'ємного ZnO. Запропоновану нами методику можна застосувати у неруйнівній експрес-діагностищі наночастинок для характеризування їхніх нелінійно-оптичних властивостей, вивчення впливу на них розмірів $і$ форми наночастинок, а також подальшого підвищення їхньої ефективності генерації гармонік. 